\title{
PENGARUH RETUURN ON ASSEETS (ROA), RETURN ON EQUITY (ROE), DAN EARNING PER SHARE (EPS) TERHADAP HARGA SAHAM PT BANK SINARMAS TBK PERIODE TAHUN 2011 - 2017
}

\author{
Reza Octovian \\ Dosen Fakultas Ekonomi Universitas Pamulang \\ Email : dosen01431@unpam.ac.id atau rezadaswar@yahoo. com
}

\begin{abstract}
ABSTRAK
Kajian ini bertujuan untuk mengetahui bagaimana pengaruh ROA (X1), ROE (X2) dan EPS (X3) pada Harga Saham (Y) PT Bank Sinarmas Tbk 2011-2017. Kaedah penyelidikan yang digunakan adalah kaedah deskriptif dengan pendekatan kuantitatif. Penduduk dalam kajian ini adalah penyata kewangan PT Bank Sinarmas Tbk dan sampel yang digunakan adalah neraca dan penyata pendapatan untuk 2011-2017. Data diperoleh dari laman web IDX (www.idx.go.id) dan Bank Sinarmas (www.banksinarmas. Hasil kajian ini menunjukkan bahawa Pulangan Aset Separa (ROA) mempunyai kesan positif dan tidak signifikan ke atas harga saham, dengan nilai signifikan 0.089. Sebahagian Pulangan Atas Ekuiti (ROE) mempunyai kesan positif yang ketara terhadap harga saham, dengan nilai signifikan 0.042. Sebahagian Pendapatan Semula (EPS) sebahagian besar mempunyai kesan positif yang signifikan terhadap harga saham, dengan nilai yang signifikan 0.008. Pada masa sama Return On Assets (ROA), Return On Equity (ROE) dan Earning Per Share (EPS) mempunyai kesan positif yang signifikan terhadap harga saham dengan nilai signifikan 0.023 .
\end{abstract}

\section{Kata Kunci : Return On Assets (ROA), Return On Equity (ROE), Earning Per Share (EPS) dan Harga Saham.}

\begin{abstract}
This study aims to determine how the effect of ROA(X $\left.X_{1}\right), \operatorname{ROE}\left(X_{2}\right)$ and EPS $\left(X_{3}\right)$ on Stock Prices (Y) PT Bank Sinarmas Tbk 2011-2017. The research method used is descriptive method with a quantitative approach. The population in this study is the financial statement of PT Bank Sinarmas Tbk and the sample used are balance sheets and income statements for 2011-2017. The data is obtained from the BEI website (www.idx.go.id) Sinarmas Bank website (www.banksinarmas.com).The results of this study indicate that partially Return on Assets (ROA) has a positive and not significant effect on the Stock Price, with a significant value of 0.089. Partially Return on Equity (ROE) has a significant positive effect on Stock Prices with a significant value of 0.042. Partially Earning Per Share (EPS) has a significant positive effect on the Stock Price, with a significant value of 0.008 . Simultaneously Return on Assets (ROA), Return on Equity (ROE) and Earning Per Share (EPS) have a significant positive effect on Stock Prices with a significant value of 0.023
\end{abstract}

Keyword: return on assets (ROA), return on equity (ROE), earning per share (EPS), stock price 


\section{PENDAHULUAN}

\section{A. Latar Belakang Masalah}

Sebuah badan atau institusi yang menggabungkan dan menganjurkan pelbagai sumber dengan niat untuk menghasilkan barangan dan perkhidmatan untuk dijual dipanggil sebuah syarikat. Tujuan syarikat ini adalah untuk memaksimumkan nilai syarikat dan meningkatkan tahap hayat para pemegang saham. Nilai pemegang saham boleh ditingkatkan dengan memaksimumkan nilai semasa atau nilai semasa semua keuntungan pemegang saham yang dijangka diperoleh pada masa akan datang .

Pada masa ini pemain pasaran modal atau pelabur perlu mendapatkan maklumat yang berkaitan dengan dinamik harga saham untuk membuat keputusan mengenai saham syarikat yang bernilai membeli untuk pelaburan. Peserta pasaran dan pelabur perlu melihat maklumat yang betul tentang prestasi kewangan syarikat, pengurusan syarikat, keadaan makroekonomi, dan maklumat lain yang relevan untuk menilai saham dengan betul .

Ketepatan penilaian saham dapat meminimumkan risiko ketika membantu para pelabur mendapatkan keuntungan yang wajar, karena diketahui bahwa investasi saham di pasar modal merupakan jenis investasi berisiko tinggi meskipun menjanjikan keuntungan yang relatif besar. Dalam melabur dalam pasaran modal sekurang-kurangnya perlu memberi perhatian kepada dua perkara, iaitu: faedah dan risiko yang diharapkan yang mungkin berlaku. Oleh itu, ia bermakna melabur dalam bentuk saham menjanjikan keuntungan besar serta berisiko .

Nilai semasa pendapatan yang akan diterima oleh pelabur pada masa akan datang dipanggil harga saham. Harga saham berada dalam arah prestasi semasa syarikat dan prestasi syarikat. Syarikat yang mempunyai pencapaian yang baik akan meningkatkan prestasi syarikat seperti yang ditunjukkan dalam penyata kewangan syarikat, jadi pelabur akan digalakkan untuk melabur dalam syarikat. Lonjakan permintaan pelabur untuk syarikat itu akan menyebabkan harga saham syarikat yang dipertikaikan juga meningkat. Harga saham sangat penting dan harus dipertimbangkan oleh pelabur dalam melabur kerana harga saham mencerminkan pencapaian penerbit. Harga saham di pasaran modal terdiri dari tiga jenis, yaitu harga tertinggi 
(harga tinggi), harga terendah (harga rendah) dan harga penutupan (harga penutupan). Harga tertinggi atau terendah adalah harga tertinggi atau terendah yang berlaku pada hari pertukaran. Harga penutupan adalah harga yang berlaku pada akhir jam pertukaran .

Penyata kewangan syarikat boleh menjadi penanda aras bagi pelabur dalam membuat keputusan pelaburan, seperti menjual, membeli, atau menanam saham. Harga saham boleh berubah pada bila-bila masa bergantung pada tahap penawaran dan permintaan pelabur untuk sahamsaham ini. Faktor dalaman dan faktor luaran syarikat adalah faktor yang boleh mempengaruhi kenaikan harga saham syarikat .

Dalam kajian ini, faktor dalaman syarikat dicerminkan dalam penyata kewangan syarikat. Faktor dalaman syarikat digunakan dalam bentuk nisbah kewangan seperti nisbah keuntungan yang disokong oleh Return on Assets (ROA), Return on Equity (ROE) dan nisbah pasaran yang disokong oleh Earning Per Share (EPS) .

Penyelidikan yang dijalankan oleh Pradipta (2012) mendapati ROA mempunyai pengaruh positif dan signifikan terhadap harga saham dalam syarikat LQ-45 di Bursa Saham Indonesia dalam tempoh 2009-2011. Sementara penyelidikan Murtiningsih (2010) menyatakan bahawa ROA tidak mempunyai pengaruh terhadap harga saham dalam Syarikat Makanan dan Minuman di IDX .

Nurfadilah (2011) menyatakan bahawa ROE mempunyai pengaruh yang signifikan terhadap harga saham. Berbeza dengan penyelidikan Utami yang menyatakan ROE tidak mempunyai pengaruh terhadap harga saham. Penyelidikan yang dijalankan oleh Shubiri (2010) mendapati bahawa sebahagian EPS mempunyai kesan positif yang signifikan terhadap harga saham di Bank-bank Perdagangan di Jordan. Berbeza dengan penyelidikan yang dijalankan oleh Iqbal Khan (2010), mendapati bahawa EPS mempunyai kesan negatif dan tidak signifikan terhadap harga saham dalam Industri Kimia dan Farmasi .

Penulis memilih nisbah ROA dan ROE sebagai faktor yang mempengaruhi harga saham, karena ROA dan ROE adalah rasio yang mewakili pengambilan semua kegiatan perusahaan. Walaupun EPS dipilih kerana EPS menunjukkan berapa banyak rupiah keuntungan yang diterima oleh para pelabur 
dalam setiap saham. Ketiga pembolehubah ini dianggap pertimbangan para pelabur dalam membeli saham dan mempunyai keuntungan dapat mempengaruhi harga saham".

Berdaasarkan iini, kajian itu diberikan tajuk "Pengaruh ROA, ROE, dan EPS Terhadap Harga Saham PT Bank Sinarmas Tbk Periode Tahun 2011-2017' .

\section{B. Identifikasi MAasalah}

Berdasarkan penjelasan di atas, dapat dinyatakan massalah yaang berkaaitan deengan peneelitian inni, yaiitu:

1. Pada tahun 2012, PT Bank Sinarmas mengalami peningkatan sebanyak $\quad 0.83 \% \quad$ dalam memperoleh keuntungan syarikat .

2. Pada tahun 2014, PT Bank Sinarmas Tbk mengalami penurunan pendapatan bersih sebanyak 3.15\% dari tahun 2013 .

3. Dalam tempoh 2014 hingga 2016, PT Bank Sinarmas Tbk mengalami peningkatan dalam meningkatkan kemakmuran pelabur dalam bentuk pengagihan dividen .

4. Pada 2012 hingga 2017, PT Bank Sinarmas Tbk mengalami peningkatan dari tahun sebelumnya dengan nilai pendapatan sekarang yang akan diterima oleh para pelabur pada masa akan datang .

\section{Pembatasan Masalah}

Bilangan masalah di atas, penulis akan membuat sekatan terrhadap masaalah yaang haanya meenjadi fokus utama dalaam kajian ini, iaitu maasalah yaang beerkaitan deengan tajuk penyelidikan dalam karya ini adalah Kesan RO A, RO E dan E PS pada Haarga Saaham PT Bank Sinarmas Tb k Tahuun 201 1- 2017.

1. ROA addalah niisbah yang menunjukkan hasil (pulangan) daripada jumlah aset yang digunakan dalam syarikat. Menurut Kasmir (2010: 201) .

2. ROE biasanya dikira menggunakan ukuran prestasi berdasarkan perakaunan dan dikira sebagai keuntungan bersih syarikat dibahagikan dengan ekuiti pemegang saham biasa, Menurut Tandelilin (2010: 315).

3. EPS atau pendapatan saham sesaham adalah satu bentuk memberi manfaat kepada para pemegang saham daripada setiap saham yang dimiliki. Menurut Fahmi (2012: 138)

4. Harga saham adalah harga saham yang terjadi di pasaran saham pada waktu tertentu ditentukan oleh peserta pasar dan ditentukan oleh permintaan dan penawaran stok yang relevan di pasar modal. Menurut Jogiyanto (2008: 167). 
5. Objektif kajian ini adalah penyata kewangan PT Bank Sinarmas Tbk yang mempunyai alamatnya di Jalan M.H. Thamrin No. 51 Jakarta 10350 Dan kajian ini dijalankan dari Januari 2019 hingga Mei 2019 di www.banksinarmas.com untuk tempoh 2011-2017.

6. Masa kajian dijalankan selama 4 bulan dari Januari 2019 hingga Mei 2019.

\section{Peruumusan Maasalah}

Berdasarkan latar belakang penyelidikan, pengenalan dan pembatasan masalah yang telah dijelaskan di atas, maka rumusan masalah dapat dicadangkan seperti berikut :

Apakah terdapat pengaruh ROA terhadap Haarga Saaham PT Ba nk Sinarrmas T bk? Apakah terdapat pengaruh ROE terhadap Haarga Saaham PT Ba nk Sinarrmas T bk? Apakah terdapat pengaruh EPS terhadap Haarga Saaham PT

Ba nk Sinarrmas T bk ? Apakah terdapat pengaruh ROA, ROE, dan EPS secara bersamasama terhadap Haarga Saaham PT

Ba nk Sinarrmas T bk?

\section{E. Tujuan dan Manfaat Penelitian}

Penelitian ini diharapkan akan memberi mannfaat kepada pihakpihak yang terkait diantaranya:
1. Unntuk mengeetahui peengaruh ROA terhadap Haga Sahham PT Bank Sinarmas Tbk.

2. Untuk mengetahui pengaruh pengaruh ROE teerhadap Haarga Saham PT Bank Sinarmas Tbk.

3. Untuk mengetahui pengaruh pengaruh EPS terhadap Haarga Sahaam PT Bank Sinarmas Tbk.

4. Untuk menentukan kesan ROA, ROE dan EPS bersama-sama pada Harga Saham PT Bank Sinarmas Tbk

\section{F. Hipotesis}

Berdasarkan perbincangan di atas, kesimpulan sementara boleh diambil dalam bentuk hipotesis penyelidikan, iaitu :

1. Diduga terdapat pengaruh ROA terhadap Harrga Saaham PT Baank Sinarrmas T bk.

2. Diduga terdapat pengaruh ROE terhadap Harrga Saaham PT Baank Sinarrmas T bk.

3. Diduga terdapat pengaruh EPS terhadap Harrga Saaham PT Baank Sinarrmas T bk.

4. Diduga terdapat pengaruh ROA, ROE, daan E PS seecara beersama-saama teerhadap ROE PT Bank Sinarmas Tbk.

Selanjutnya maka hipotesis dirumuskan ke dalam persamaan statistik uji regresi yang kemudian akan dianalisis dan dibahas, berikut persamaan hipotesis statistik : 
$\mathrm{Ha}_{1}$ : Ada pengaruh RO A mengawal perniagaan yang dilakukan terhadap Haarga Saaham PT Bank Sinarmas Tbk.

$\mathrm{Ho}_{1}$ : Tidak ada pengaruh ROA terhadap Harga Saham PT Bank Sinarmas Tbk.

oleh anggota organisasi dan penggunaan sumber yang ada untuk mencapai matlamat organisasi yang telah digunakan sebelum ini. $\mathrm{Ha}_{2}$ : Ada pengaruh $\mathrm{ROE}$ terhadap Harga Saham PT Bank Sinarmas Tbk.

$\mathrm{Ho}_{2}$ : Tidak ada pengaruh $\mathrm{ROE}$ terhadap Harga Saham PT Bank Sinarmas Tbk.

$\mathrm{Ha}_{3}$ : Ada pengaruh EPS terhadap Harga Saham PT Bank Sinarmas Tbk.

$\mathrm{Ho}_{3}$ : Tidak ada pengaruh EPS terhadap Harga Saham PT Bank Sinarmas Tbk.

$\mathrm{Ha}_{4}$ : Ada pengaruh ROA, ROE, dan EPS secara bersamasama terhadap Harga Saham PT Bank Sinarmas Tbk.

$\mathrm{Ho}_{4}$ : Tidak ada pengaruh ROA, ROE dan EPS secara bersama-sama terhadap Harga Saham PT Bank Sinarmas Tbk.

\section{TINJAUAN PUSTAKA}

\section{A. Manajemen \\ 1. Pengertian Manajemen}

Secara umum, definisi pengurusan adalah aktiviti untuk mengawal selia, memimpin, mengurus, membangun dan

\section{B. Manajemen Keuangan \\ 1. Pengertian Keuangan}

Kewangan adalah istilah yang sering kita dengar. Istilah ini digunakan secara meluas dalam bidang ekonomi, khususnya dalam perakaunan. Di samping itu, istilah kewangan juga boleh digunakan 
dalam interaksi harian. Dalam penggunaan istilah dalam kehidupan seharian, kewangan biasanya difahami sebagai keadaan wang atau keadaan ekonomi seseorang.

Pada pendaapat Lee Cutre dan Haseenack di Ryanto (2010:3) bahwa "Keuangan adalah pembelanjaan yang meliputi keseluruhan usaha untuk mempersiapkan dan mengatur penarikan dan penggunaan dana dimana disini termasuk juga perencanaan beserta pelaksanaannya .

\section{Pengertian Manaajemen Kuangan}

Pengurusan Kewangan adalah semua aktiviti atau aktiviti syarikat yang berkaitan dengan cara mendapatkan pendanaan modal kerja, menggunakan atau memperuntukkan dana, dan menguruskan aset yang dimiliki untuk mencapai objektif utama syarikat.

\section{Funngsi Manaajemen Keuuangan}

Fungsi pengurusan kewangan termasuk Keputusan Pelaburan, Fungsi Pembiayaan dan Keputusan Pengurusan Aset. Takrif pengurusan kewangan mengikut Grestenberg Hamper adalah sama seperti James Van Horne, iaitu bagaimana syarikat dapat memperoleh, menggunakan dananya sehingga keuntungan dari

\section{Laporan Keuangan}

Dalaam praaktiknya, penyata kewangan oleeh syarikat tidak dibuat secara sembarangan, tetapi harus disediakan dan disusun sesuai dengan norma atau standar yang berlaku. Ini perlu dilakukan supaya penyata kewangan mudah dibaca dan difahami. Penyata kewangan yang dibentangkan oleh syarikat sangat penting untuk pengurusan dan pemilik syarikat. Di samping itu, terdapat banyak pihak yang memerlukan dan mempunyai kepentingan dalam penyata kewangan yang dibuat oleh syarikat, seperti kerajaan, pemiutang, pelabur, dan pembekal .

\section{Retturn on Assets (ROA)}

Return on Assets (ROA) ROA adalah nisbah yang digunakan untuk mengukur keuntungan bersih yang diperoleh daripada penggunaan aset. Ini akan meningkatkan lagi nilai syarikat kepada pelabur. Meningkatkan nilai syarikat menyebabkan syarikat semakin diperhatikan oleh pelabur, kerana kadar pulangan akan lebih tinggi. Ini juga akan memberi kesan bahawa harga saham syarikat dalam Pasaran Modal juga akan meningkat supaya 
ROA akan mempengaruhi harga saham syarikat.

\section{E. Return On Equity (ROE)}

Keupayaan syarikat dapat menjana keuntungan dari modal sendiri yang digunakan. Dengan mengetahui nisbah ini, akan diketahui sama ada syarikat menggunakan aset modal sendiri dalam aktiviti operasi syarikat. Nisbah ini juga memberikan ukuran yang lebih baik dari keuntungan syarikat kerana ia menunjukkan keberkesanan pengurusan dalam menggunakan modal untuk memperoleh pendapatan.

\section{F. Earnning peer Shhare (EPS)}

Earning per Share (EPS) adalah nisbah yang menunjukkan saiz keuntungan bersih syarikat yang sedia untuk diedarkan kepada semua pemegang saham syarikat. Pelabur yang membeli saham bermakna pelabur membeli prospek syarikat, yang dicerminkan dalam perolehan sesaham, jika pendapatan sesaham lebih tinggi, prospek syarikat lebih baik, sebaliknya jika perolehan sesaham yang lebih rendah bermakna kurang baik.

\section{METODOLOGI PENELITIAN}

\section{A. Ruuang Lingkup Penelitian \\ 1. Lokasi Peneelitian}

Syarikat yang menjadi sasaran penyelidikan ini ialah PT Bank Sinarmas Tbk yang terletak di Jalan M.H. Thamrin No. 51 Jakarta 10350. Proses ini merangkumi seluruh karya bermula dari penentuan tajuk ke proses pelaporan hasil penyelidikan .

\section{Waktu Penelitian}

Apabila kajian itu dijalankan selama 4 bulan dari Januari 2019 hingga Mei 2019. Penyelidikan ini dijalankan secara berperingkat mengikut tahap keperluan penulis, bermula dengan penyediaan menulis cadangan tajuk penyelidikan, cadangan seminar, penyempurnaan bahan cadangan, membuat instrumen penyelidikan, mengumpulkan data primer dan sekunder, memproses data, hingga persiapan akhir .

\section{Objek Penelitian}

Penyelidikan ini termasuk dalam skop penyelidikan pengurusan kewangan, secara khusus membincangkan pengaruh ROA, ROE dan EPS pada Harga Saham, PT Bank Sinarmas Tbk 2011-2017.

\section{B. Metodde Peenentuan Poopulasi daan Saampel}

1. Populassi

Kajian ini menggunakan polpulasi data laporan kewangan PT Bank Sinarmas Tbk.

\section{Sampel}


Adapun yang dijadikan sampel dalam kajian ini adalah data penyata kewangan dalam bentuk (lembaran imbangan dan penyata pendapatan PT Bank Sinarmas Tbk, tempoh 20112017) .

\section{Metode Pengumpulan Data}

Kaedah pengumpulan data yang digunakan dalam kajian ini adalah data sekunder. Data sekunder adalah data primer yang telah diproses dan dikemukakan oleh pengumpul data utama, atau oleh pihak lain.

\section{Metode Analisis Data}

\section{Ujji Staatistiik Deskkriptif}

Statistik deskriptif adalah statistik yang digunakan untuk menganalisis data dengan menerangkan data yang telah dikumpulkan sebagai hasil atau keputusan tanpa bermaksud membuat kesimpulan umum.

\section{Pengujiaan Assumsi Kllasik}

Menguji andaian
diperlukan sebelum
hipotesis.
a. Uji Normalitas
b. Uji Heteroskedastisitas
c. Uji Autokorelasi
d. Uji Multikolinearitas
e. Uji Linearitas

\section{Koefisieen Deeterminasi $\left(\mathbf{R}^{2}\right)$}

Ujian atau ujian penentuan R2 merupakan langkah penting dalam regresi, kerana dapat memberi tahu apakah model regresi anggaran atau tidak, atau dengan kata lain angka dapat mengukur seberapa dekat garis regresi diukur ke data aktual.

\section{Analissis Regrresi Lianr Berrganda}

Kaedah regresi linear berganda adalah cara untuk meramalkan nilai $Y$, jika terdapat lebih daripada satu pemboleh ubah bebas $\mathrm{X}$ yang mempengaruhi $\mathrm{Y}$, termasuk dalam persamaan regresi.

$\mathrm{Y}=\mathrm{a}+\mathrm{b}_{1} \mathrm{X}_{1}+\mathrm{b}_{2} \mathrm{X}_{2}+\mathrm{b}_{3} \mathrm{X}_{3}$

Dimana :

$\mathrm{Y}=$ Variabel terikat (Harga Saham)

$\mathrm{X}_{1}=$ Variabel bebas ke satu (ROA)

$\mathrm{X}_{2}=$ Variabel bebas ke dua (ROE)

$\mathrm{X}_{3}=$ Variable bebas ke tiga (EPS)

a $=$ Konstanta

\section{HASIL PENELITIAN DAN HASIL} PEMBAHASAN

\section{Hasil Ujji Asumsi Klaasik}

a. Hasil Uji Normaliitas

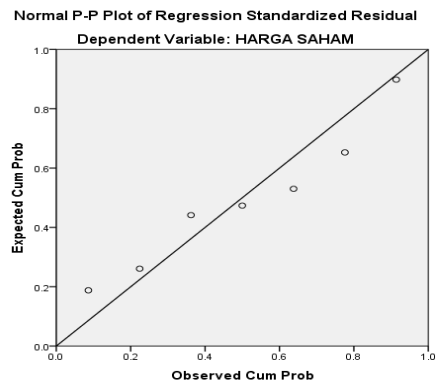

\section{Gambbar 1 Graafik P-P Ploot}

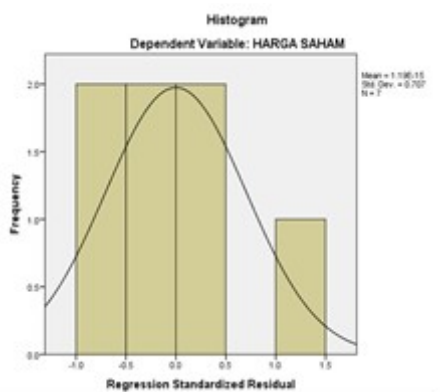




\section{Gammbar 2 Graafik Hiistogram}

Berdasarkan hasil uji normalitas terlihat bahwa data berdistribusi dengan normal, terlihat dari grafik p-p plot yang titik - titiknya mendekati garis diagonal. Berdasarkan grafik histogram terlihat bahwa garis sejajar dengan menyerupai gunung.

b. $\mathbf{H}$

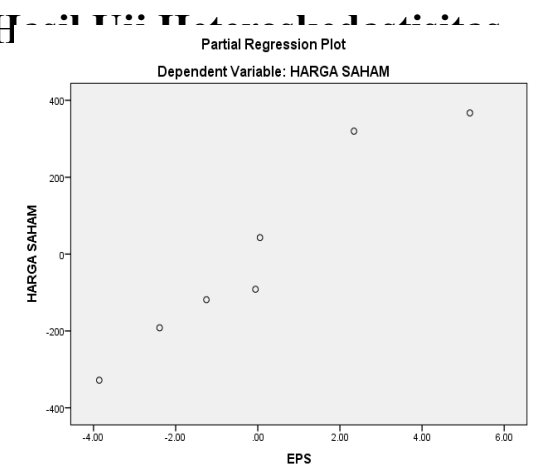

Gambar 3 EPS terhadap HS
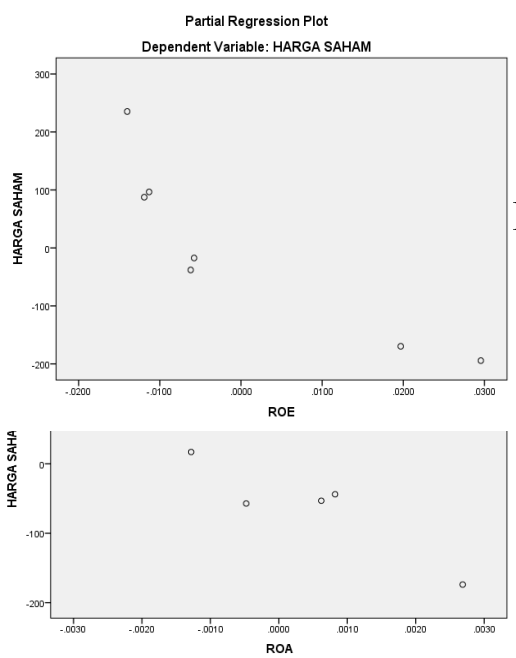

\section{Gambar 5 ROA terhadap HS}

Berdasarkan gambar di atas hasil uji heteroskedastisitas terlihat bahwa tidak terjadi heteroskedastisitas karena titiknya tidak membentuk pola, tidak mengumpul dan berada di atas dan di bawah angka nol.

\section{c. Uji Autokorelasi}

1) Hasil Uji Durbin Watson

Tabel 1 Hasil Uji DW

\begin{tabular}{|l|r|r|r|r|r|}
\hline Model & $R$ & $\begin{array}{c}\text { R } \\
\text { Square }\end{array}$ & $\begin{array}{r}\text { Adjusted } \\
\text { R Square }\end{array}$ & $\begin{array}{c}\text { Std. Error } \\
\text { of the } \\
\text { Estimate }\end{array}$ & Durbin-Watson \\
\hline 1 & $.971^{a}$ & .943 & .886 & 98.094 & 1.654 \\
\hline a. Predictors: (Constant), EPS, ROE, ROA \\
\hline b. Dependent (Variable:HARGASAHAM
\end{tabular}

dinyatakan tidak terdapat autokorelasi karena memiliki nilai antara -2 sampai $+2(1,654)$.

\section{2) Hasil Uji Run Test}

Tabel 2

Hasil Uji Run Test

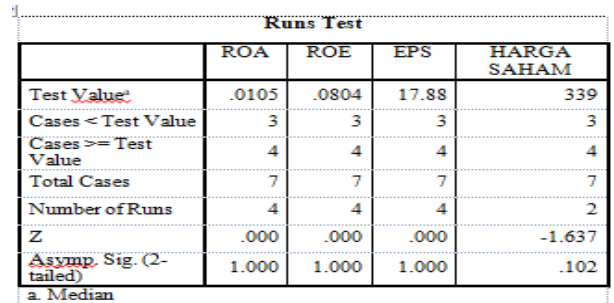

asymp sig. 2-tailed $>0.05$.

\section{d. Hasil Uji Multikolinearitas}

Tabel 3

Hasil Uji Multikolinearitas

\begin{tabular}{|l|r|r|}
\hline \multirow{2}{*}{ Model } & \multicolumn{2}{|c|}{ Collinearity Statistics } \\
\cline { 2 - 3 } & Tolerance & \multicolumn{1}{c|}{ VIF } \\
\hline (Constant) & .242 & 4.132 \\
ROA & .495 & 2.022 \\
ROE & .284 & 3.521 \\
EPS & & \\
AHAM
\end{tabular}

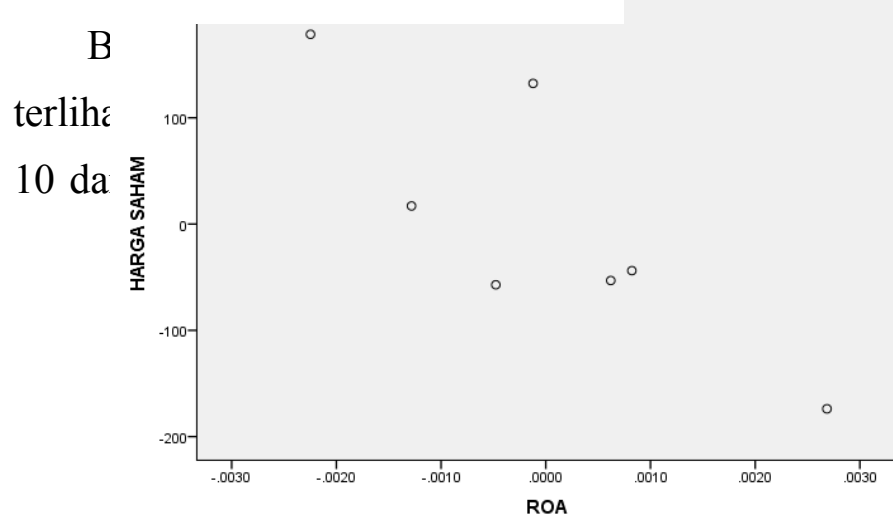


hal ini membuktikan bahwa tidak terjadi multikolinearitas.

\section{Hasil Uji Hipotesis}

a. Hasil Uji Signifiansi (Uji Parsial)

Tabel 4

\section{Hasil Uji t}

\begin{tabular}{|c|c|c|c|c|c|c|}
\hline \multirow{2}{*}{\multicolumn{2}{|c|}{ Model }} & \multicolumn{2}{|c|}{$\begin{array}{l}\text { Unstandardized } \\
\text { Coefficients }\end{array}$} & \multirow{2}{*}{$\begin{array}{c}\begin{array}{c}\text { Standardized } \\
\text { Coefficients }\end{array} \\
\text { Beta }\end{array}$} & \multirow[t]{2}{*}{$t$} & \multirow[t]{2}{*}{ Sig. } \\
\hline & & B & Std. Error & & & \\
\hline \multirow{4}{*}{1} & (Constant) & 195.096 & 144.857 & & 1.347 & .271 \\
\hline & ROA & -62315.361 & 25152.335 & -.718 & -2.478 & .089 \\
\hline & ROE & -7884.592 & 2313.088 & -.706 & -3.409 & .042 \\
\hline & EPS & 83.288 & 13.305 & 1.567 & 6.260 & .008 \\
\hline
\end{tabular}

EPS, ROE dan ROA memiliki kesan yang ketara ke atas harga saham kerana ia mempunyai nilai yang signifikan pada harga saham, kerana ia mempunyai nilai yang signifikan $<0.05$.

\section{b. Hasil Uji Simultan (Uji F)}

Tabel 5

Hasil Uji F

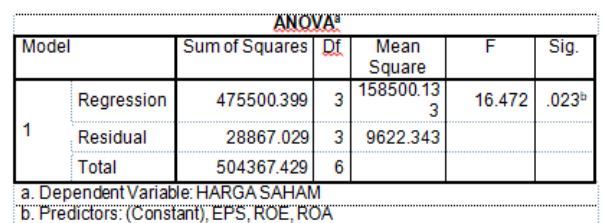

3. Hasil Koefisien Determinasi

Tabel 6 Hasil Koefisien Determinasi

\begin{tabular}{|c|c|c|c|c|c|}
\hline \multicolumn{6}{|c|}{ Model Summary } \\
\hline Model & $\mathrm{R}$ & $\begin{array}{c}\mathrm{R} \\
\text { Square }\end{array}$ & $\begin{array}{l}\text { Adjusted } \\
\text { R Square }\end{array}$ & $\begin{array}{l}\text { Std. Error } \\
\text { of the } \\
\text { Estimate }\end{array}$ & Durbin-Watson \\
\hline 1 & $.971^{\mathrm{a}}$ & .943 & .886 & 98.094 & 1.654 \\
\hline
\end{tabular}

Berdasarkan hasil koefisien determinasi terlihat bahwa EPS,
ROE dan ROA memiliki pengaruh $88,6 \%$ terhadap harga saham sedangkan sisanya $100 \%-88,6 \%$ $=11,40 \%$ dipengaruhi vaiabel lain yag tidak ada dalam penelitian ini.

\section{Hasil Uji Regresi Linier Berganda}

Tabel 7

Hasil Koefisien Regresi Linier Berganda

\begin{tabular}{|c|c|c|c|c|c|c|}
\hline \multirow{2}{*}{\multicolumn{2}{|c|}{ Model }} & \multicolumn{2}{|c|}{$\begin{array}{c}\text { Unstandardized } \\
\text { Coefficients }\end{array}$} & \multirow{2}{*}{$\begin{array}{c}\begin{array}{c}\text { Standardized } \\
\text { Coefficients }\end{array} \\
\text { Beta }\end{array}$} & \multirow[t]{2}{*}{ 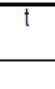 } & \multirow[t]{2}{*}{ Sig. } \\
\hline & & $B$ & Std. Error & & & \\
\hline \multirow{4}{*}{1} & (Constant) & 195.096 & 144.857 & & 1.347 & .271 \\
\hline & ROA & -62315.361 & 25152.335 & -.718 & -2.478 & .089 \\
\hline & ROE & -7884.592 & 2313.088 & -.706 & -3.409 & .042 \\
\hline & EPS & 83.288 & 13.305 & 1.567 & 6.260 & .008 \\
\hline
\end{tabular}

Dengan demikian maka dapat dibentuk persamaan regresi linier berganda sebagai berikut:

$$
\begin{aligned}
\mathrm{Y}= & 195,096-62315,361\left(\mathrm{X}_{1}\right)- \\
& 7884,592\left(\mathrm{X}_{2}\right)+83,288\left(\mathrm{X}_{3}\right) \\
& +\mathrm{e}
\end{aligned}
$$

\section{KESIMPULAN DAN SARAN}

\section{A. Kesimpulan}

Berdasarkan hasil analisis dalam bab sebelumnya, kesimpulan berikut dapat dibentangkan:

1. Return On Assets (ROA) yang berpengaruh secara positif dan tidak penting kepada harga saham PT Bank Sinarmas Tbk. Ia dapat dilihat bahawa nilai dikira untuk ROA ialah 2.478. Nilai ini akan dibandingkan dengan jadual 2.35336 dalam jadual edaran t. Di 
mana $\mathrm{t}$ hitung $=2.478>\mathrm{t}$ jadual $=$ 2.35336 dan nilai signifikansi $0.089>0.05$ jadi kesimpulan menunjukkan bahawa Ho ditolak dan Ha diterima, maka hipotesis ini menyatakan bahawa ROA mempunyai kesan positif dan tidak signifikan pada Harga Saham

2. Pulangan atas Ekuiti (ROE) sebahagiannya positif dan signifikan ke atas Harga Saham PT Bank Sinarmas Tbk. Ia dapat dilihat bahawa nilai yang dikira untuk ROE ialah 3.409. Nilai ini akan dibandingkan dengan jadual 2.35336 dalam jadual edaran t. Di mana $\mathrm{t}$ menghitung $=3.409 \mathrm{>}$ jadual $=2.35336$ dan nilai penting ialah $0.042<0.05$. Jadi kesimpulan menunjukkan bahawa Ho ditolak dan Ha diterima, maka hipotesis ini menyatakan bahawa ROE mempunyai kesan positif dan signifikan terhadap harga saham.

3. Earning Per Share (EPS) berpengaruh secara positif dan signifikan ke atas harga saham PT Multistrada Arah Sarana Tbk. Ia dapat dilihat bahawa nilai dikira untuk EPS ialah 6.260. Nilai ini akan dibandingkan dengan jadual 2.35336 dalam jadual edaran t. Di mana $\mathrm{t}$ hitung $=6.260>\mathrm{t}$ jadual $=$ 2.35336 dan nilai kepentingan ialah $0.008<0.05$. Oleh itu, kesimpulan menunjukkan bahawa Ho ditolak dan Ha diterima, maka hipotesis ini menyatakan bahawa EPS mempunyai kesan positif dan signifikan terhadap harga saham.

4. Pulangan Aset, Pulangan $\mathrm{Ke}$ atas Ekuiti dan Pendapatan Sesaham bersama (serentak) mempunyai kesan positif yang signifikan terhadap Harga Saham PT Bank Sinarmas Tbk. Ia dapat dilihat bahawa keputusan Ujian $F$ menunjukkan nilai Fcount sebanyak 16.472 manakala Faktor 4.35 bermakna $16.472>4.35$ dengan nilai penting $0.023<0.05$, maka HO diterima dan H1 ditolak. Ini menunjukkan bahawa pembolehubah bebas secara serentak mempengaruhi pembolehubah bergantung, hipotesis ROA, ROE, dan EPS yang dicadangkan pada masa yang sama mempengaruhi harga saham yang diterima. Ini bermakna bahawa sebarang perubahan yang berlaku kepada pembolehubah bebas, iaitu ROA, ROE, dan EPS serentak atau bersama-sama akan menjejaskan Harga Saham PT Bank Sinarmas Tbk

\section{B. Saran}

Berdasarkan pada kesimpulan di atas, penulis memberikan saran dan masukan bagi penelitian selanjutnya yaitu: 


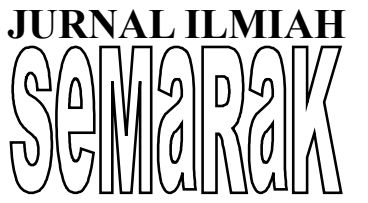

1. Perusahaan agar menjaga kinerja keuangannya sehingga harga sahamnya semakin baik walaupun terkena dampak perubahan Earning Per Share

2. Perusahaan agar meningkatkan Return On Equity (ROE) nya agar harga sahamnya meningkat.

3. Perusahaan agar selalu meningkatkan Return On Assets agar harga sahamnya semakin meningkat.

4. Kajian lanjut perlu dilakukan mengenai pembolehubah yang mempengaruhi Harga Saham, terutama di PT Bank Sinarmas Tbk .

\section{DAFTAR PUSTAKA}

Agoes, Sukrisno dan Estralita Trisnawati. Akuntansi Perpajakan. Jakarta: Salemba Empat.

Al-Shubiri, $\quad$ Faris. 2010. Determinantof Capital Structure Choice: A Case Study of Jordanian Industrial Companies. An-Najah Univ. J. of Res. (Humanities), 24 (8), 2458-2494.

Darmadji, $\mathrm{T}$ dan Fakhrudin M.H. 2006. Pasar Modal di Indonesia Pendekatan Tanya Jawab. Jakarta: Salemba Empat.

Darsono dan Ashari. 2009. Pedoman Praktis Memahami Laporan
Keuangan. Yogyakarta: Andi.

Fahmi, Irham. 2012. Analisis Kinerja Keuangan. Bandung: Alfabeta

Hanafi, Mahmud M. dan Halim, Abdul. 2009. Analisis Laporan Keuangan. Edisi Keempat. Yogyakarta: YKPN.

Harahap, Sofyan Syafri. 2009. Teori Kritis Laporan Keuangan. Jakarta: Bumi Aksara.

Handoko, T. Hani. 2011. Manajemen Personalia dan Sumberdaya Manusia. Yogyakarta: Penerbit BPFE.

Hasibuan, Malayu S.P. 2016. Manajemen Sumber Daya Manusia. Edisi Revisi. Jakarta: Penerbit PT Bumi Aksara.

Kasmir. 2010. Analisis Laporan Keuangan. Jakarta: PT Raja Grafindo Persada.

Kasmir. 2012, Analisis Laporan Keuangan. Jakarta : PT. Raja Grafindo Persada.

Kasmir. 2013. Analisis Laporan Keuangan. Rajawali Pers: Jakarta.

Keown, John D. Martin, J. William Petty, David F. Scott, JR. 2011. Manajemen Keuangan: Prinsip \& Penerapan. PT. Indeks, Jakarta.

Munawir, S. 2010. Analisis laporan Keuangan Edisi keempat. Cetakan Kelima Belas. Yogyakarta: Liberty.

Murtiningsih dan Suyanti. 2011. Membuat Tepung Umbi dan 
Variasi Olahannya. Jakarta: Agro Media Pustaka.

Nurfadilah. 2011. Analisis pengaruh Earning Per share, debt to equity ratio dan return on equity terhadap harga saham PT Unilever Indonesia Tbk. Jurnal. STIE Muhamadyah Samarinda.

Paramasivan dan Subramanian, 2009. Financial Management. New Delhi New Age International (P) Ltd., Publishers

Priyatno. 2008. Mandiri Belajar SPSS - Bagi Mahasiswa dan Umum. Yogyakarta: MediaKom.

Riyanto. 2012. Dasar-dasar Pembelanjaan, Edisi 4. Yogyakarta: BPFE.

Sarwono, Jonathan. (2012). Metode Riset Skripsi Pendekatan Kuantitatif Menggunakan Prosedur SPSS (Edisi Pertama). Jakarta: PT Elex Media Komputindo.

Solihin, Ismail. 2009. Corporate Social Responsibility from Charity to Sustainability. Jakarta: Salemba Empat.

Sugiyono. 2006. Metode Penelitian Kuantitatif Kualitatif dan $R \& D$. Bandung: Alfabeta.

Sugiyono. 2014. Metode Penelitian Pendidikan Pendekatan Kuantitatif, Kualitatif Dan $R \& D$. Bandung: Alfabeta.

Sugiyono. 2015. Metode Penelitian Pendidikan (Pendekatan
Kuantitatif, Kualitatif dan $R \& D)$. Penerbit CV. Alfabeta: Bandung.

Tandelilin, Eduardus. 2010. Portofolio dan Investasi Teori dan Aplikasi. Edisi pertama. Yogyakarta : Kanisius.

Terry, G R. 2010. Manajemen Sumber Daya Manusia. Edisi Pertama. Cetakan Pertama. Jakarta : Penerbit Kencana.

Wijayanto, Dian. 2012. Pengantar Manajemen. Jakarta: PT Gramedia Pustaka Utama.

www.banksinarmas.com. Laporan Keuangan PT. Bank Sinarmas

www.duniainvestasi.com

www.idx.co.id. 2014. Laporan Keuangan PT. Bank Sinarmas yang Terdaftar

\section{Skripsi}

Amanda, Astrid dkk. 2012. Pengaruh Debt To Equity Ratio, Return On Equity, Earning Per Share, dan Price Earning Ratio Terhadap Harga Saham (Studi pada Perusahaan Food and Beverages yang Terdaftar di BEI Tahun 2008-2011. Jurnal.

Bachtiar, Yanuar. 2012. Kinerja Keuangan Terhadap Harga Saham Pada Perusahaan Sektor Agriculture di Bursa Efek Indonesia, Sekolah Tinggi Ilmu Ekonomi Indonesia Banjarmasin. Jurnal Ilmu-ilmu Sosial Volume 4 Nomor 2. Banjarmasin. 
Dita, Ines Farah. 2013. Pengaruh Kinerja Keuangan Terhadap Harga Saham". Penelitian ini dilakukan pada perusahaan otomotif yang terdaftar di Bursa Efek Indonesia periode 2009-2011. Skripsi. Malang: Fakultas Ekonomi. Universitas Brawijaya.

Itabillah, E Amalia.2013.Pengaruh $C R, \quad Q R, N P M, R O A, E P S$, ROE, DER dan PBV terhadap harga saham perusahaan Property dan Real Estate yang terdaftar di Bursa Efek Indonesia. Universitas Maritim Raja Ali Haji.

Ratih, Dorothea, Apriani E.P dan Saryadi. 2013. Pengaruh EPS, PER, DER, ROE, Terhadap Harga Saham Pada Perusahaan Sektor Pertambangan Yang Terdaftar Di Bursa Efek Indonesia Tahun 2010-2012. Jurnal Sosial dan Politik Vol 3, No. 1 2014.

Sari, Puspita. 2014. Pengaruh Current Ratio, Net Profit Margin, Return On Asset, Debt to Equity Ratio, Total Asset Turnover dan Earning Per Share terhadap Harga Saham Perusahaan Industri Barang Konsumsi yang Go Public di Bursa Efek Indonesia Periode Tahun 2010-2013. Universitas Maritim Raja Ali Haji.

Purnomo, S., \& Pasaribu, V. L. D.

(2019). Pergerakan Harga Saham PT Adaro Energy Tbk (ADRO) Pada Pengumuman Dividen Interim Tahun Buku 2018. Jurnal Ekonomi Efektif, 2(4). 